\title{
Risk and impact of herpes zoster among COPD patients: a population-based study, 2009-2014
}

\author{
Cintia Muñoz-Quiles ${ }^{1,3^{*}}$ (D), Mónica López-Lacort ${ }^{1}$ and Javier Díez-Domingo ${ }^{1,2}$
}

\begin{abstract}
Background: The objective of this study was to assess the incidence of Herpes Zoster ( $\mathrm{HZ}$ ) among patients with chronic obstructive pulmonary disease (COPD) and the impact of $\mathrm{HZ}$ on the underlying COPD.

Methods: A retrospective cohort of all subjects older than 49 years was followed up between 2009 and 2014 using population and health databases of Valencia Region (Spain). HZ and COPD were identified using ICD-9 codes, differentiating COPD patients with inhaled corticosteroids prescriptions (COPD-ICS). The incidence of HZ was compared among 3 groups [non-COPD, COPD and COPD-ICS populations] and use of healthcare resource due to $\mathrm{HZ}$ for 6 months following $\mathrm{HZ}$ diagnosis through different statistical generalized linear models (GLM). We also compared resources consumption due to COPD before and after $\mathrm{HZ}$.

Results: The cohort consisted of 2,289,485 subjects, including 161,317 COPD patients of which 29,708 were COPD-ICS. HZ incidence rates were 11 (95\% confidence interval [Cl]: 10.7-11.4) and 13 (95\% Cl: 12.3-13.8) cases/1000 persons-year for COPD and COPD-ICS populations respectively. Incidence increased with age in all groups. The risk of HZ rose by 45 and 61\% among COPD and COPD-ICS patients respectively compared to non-COPD (95\% credible intervals [Crl]: 1.41-1.5 and 1.52-1.71 respectively). COPD patients consumed more resources due to their $\mathrm{HZ}$ than non-COPD. There was no statistically significant impact of the $\mathrm{HZ}$ on the resources consumed due to COPD during the 6 months post $-\mathrm{HZ}$ compared to the 6 months pre- $\mathrm{HZ}$.
\end{abstract}

Conclusions: The presence of COPD increases the risk, severity and impact of zoster episodes.

Keywords: Herpes zoster (HZ), Chronic obstructive pulmonary disease (COPD), Epidemiology, Population-based study, Vaccine

\section{Background}

Herpes Zoster (HZ) is a severe disease resulting from the reactivation of Varicella Zoster Virus (VZV), which remains latent in the nervous system after primary infection (Varicella) [1]. This reactivation seems to be a result of a waning of VZV-specific cell-mediated immunity [2], as occurs with ageing or in individuals with immunosuppressive conditions. HZ can result in chronic pain which is its most common complication (post-herpetic neuralgia, PHN) [3]. Many patients with PHN develop severe

\footnotetext{
*Correspondence: cinquiles@gmail.com

'Vaccine Research. Fundación para el Fomento de la Investigación Sanitaria y Biomédica de la Comunitat Valenciana, FISABIO-Public Health, Valencia, Spain ${ }^{3}$ Vaccine Research Area, FISABIO-Public Health, Avda. Cataluña, 21, 46020 Valencia, Spain

Full list of author information is available at the end of the article
}

physical, occupational and social disabilities because of enduring pain. HZ and PHN reduce life quality, and increase healthcare costs [4].

Incidence of $\mathrm{HZ}$ increases strongly with age, being higher after the age of 50 and affecting up to $50 \%$ of people who live to 85 years $[5,6]$. Beyond age, concomitant diseases increase the risk, the severity and the impact of $\mathrm{HZ}$ in advanced age population. Diabetes mellitus, chronic obstructive pulmonary disease (COPD) or cardiovascular diseases have been identified as risk factors for $\mathrm{HZ}$ and PHN [7-10]. The prevalence and the impact of chronic diseases have been increasing constantly the last decades [11, 12]. Maintaining the affected population healthy constitutes a priority $[13,14]$, avoiding exacerbations provoked by infectious diseases, which might render 
the affected individual dependent on their families or the healthcare system.

Vaccinations represent important preventive tools against infections. A live-attenuated vaccine for the prevention of HZ (Zostavax, Sanofi Pasteur MSD) was approved in 2006 and has been since licensed in many countries for adults older than 50 years of age $[15,16]$. Its effectiveness has been assessed in several studies, which showed similar results in healthy subjects and individuals with chronic diseases [17-19]. Currently in Spain, there are efforts to introduce recommendations for $\mathrm{HZ}$ vaccination. Given the relatively high cost of the zoster vaccine the identification of populations at increased risk for $\mathrm{HZ}$ constitutes an important research question.

COPD is the fourth cause of death worldwide, projected to be the third by 2020, and ranks fifth in terms of disease burden [12]. COPD patients have higher risk of being affected by invasive diseases and have frequently co-morbidities making COPD management complicated. There is evidence that autoimmunity plays a role in the pathogenesis of COPD [20]. The increased numbers of T-cells and B-cells in the lungs of COPD patients, the detection of auto-antibodies in their serum and the findings in animal models [20-22] support this hypothesis. This immune system impairment could be associated with an increased HZ risk in COPD patients.

Few studies have addressed the risk of developing $\mathrm{HZ}$ in COPD patients, but none the impact of COPD on the severity, complications of $\mathrm{HZ}$ and healthcare expenditure. Moreover, their results regarding the relationship between $\mathrm{HZ}$ and the usage of inhaled corticosteroids (ICS) in severe COPD are controversial [7, 23-25]. In this population-based study we considered the COPD impact on the risk and severity of $\mathrm{HZ}$, estimating the $\mathrm{HZ}$ incidence in these patients and the healthcare resources utilization attributed to the $\mathrm{HZ}$. We also assessed the HZ impact on the COPD patients by looking at the ensuing exacerbation of the disease, measured in terms of increased outpatient visits, hospitalizations and medication prescriptions after the $\mathrm{HZ}$ episode. These relationships were evaluated considering COPD patients with and without ICS treatment (COPD-ICS).

\section{Methods}

This is a population-based study to assess the impact of underlying COPD on the risk of suffering $\mathrm{HZ}$, the associated healthcare resources use, and the HZ impact on COPD patients using databases of the Valencia Region. The methods used in this study were similar to those used in a previous work from our group [10], briefly:

\section{Setting and study population}

In 2015 the Valencia Region of Spain had 4,980,689 inhabitants [26] registered. Over $98 \%$ were insured by the
Regional Health System (RHS) [27], which consists of 24 Health Departments [10]. All visits to primary care and hospital admissions are recorded in relevant clinical databases.

Around $37 \%$ of the population in the Valencia Region is $\geq 50$ years old. The cohort of the study included all subjects' aged 50 years or older, insured by the RHS and living in the Valencia Region between 1st of January 2009 and 31st of December 2014. We excluded patients with immunosuppressive conditions [10, 28].

\section{Data source: Electronic databases}

Primary care electronic medical records (SIA) and all medical visits with ICD-9-CM recorded diagnoses are registered [29]. The minimum basic data set (MBDS) was used for hospitalization, which collects diagnosis and procedures as an assessment of medical activity also ICD-9-CM coded. For medication information we used the Care Provision Management (GAIA) created by the Department of Health, which contains all the registers regarding prescription and dispensation. The unique personal identification number (SIP) allows to link data from all these databases $[6,10]$.

\section{Case definitions}

The first appearance of an ICD-9-CM code related to HZ (053.*) in SIA or MBDS was considered an incident case of HZ [10]. When a HZ code appeared 6 months after a previous $\mathrm{HZ}$ registry, it was considered a recurrent $\mathrm{HZ}$ case $[6,10]$.

COPD patients were defined when a diagnostic ICD9-CM code for COPD (491, 492 or 496) was recorded in SIA or in MBDS. A COPD case was considered severe, when an inhaled corticosteroids prescription (COPDICS) was issued.

\section{Variables}

Gender, age, health department, nationality, social exclusion risk and rural/urban residence were recorded for each individual [10]. Diabetes and heart failure (HF) were considered also as co-variables and patients were identified when a diagnostic ICD-9 code for HF (428428.9) or for diabetes (250.*) was detected and when a prescription or dispensation for insulin and/or oral antidiabetic drugs was recorded in GAIA.

\section{Statistical analysis}

The statistical analysis was described previously [10]:

Incidence rates of $\mathrm{HZ}$ and $95 \% \mathrm{CI}$ were estimated by sex, age and year by the Poisson exact method. We calculated and compared the HZ incidence among nonCOPD, COPD and COPD-ICS populations and the healthcare resource use caused by HZ during 6 months 
following the $\mathrm{HZ}$ diagnosis. Recurrence rates of $\mathrm{HZ}$ were also estimated [10].

The risk of suffering HZ in COPD patients was calculated using Bayesian mixed Poisson regression, adjusting by year, gender, health department (as a random effect), other co-morbidities (diabetes and HF) and group variable as a random effect to resolve the over-dispersion issue [10].

To compare the use of healthcare resources between the groups we focused on the number and length of hospitalizations and number of outpatient visits with a HZ code, prescriptions for $\mathrm{HZ}$ and number and duration of sick leave due to $\mathrm{HZ}$ during the six months after the $\mathrm{HZ}$ diagnosis (See Additional file 1 for ATC codes, drug type and drug name of the medication registered for $\mathrm{HZ}$ and $\mathrm{PHN}$ ). In order to compare the COPD and the non-COPD groups we performed different GLM depending on the outcome variable (The GLM details are showed in Additional file 2).

The impact of the HZ on the COPD was evaluated in COPD subjects during the six months pre- and post-HZ. We compared the healthcare resources utilization between both periods. In order to compare the pre- and post-HZ periods different GLM were implemented (For GLM details see Additional file 2) [10].

\section{Ethical considerations}

The study protocol was approved by the Ethics Committee of Dirección General de Salud Pública / Centro Superior de Investigación en Salud Pública.

\section{Results}

The final cohort included 2,289,485 Valencia Region residents, between 1st of January 2009 and 31st of December 2014. They were older than 50 years of age. This cohort included 161,317 COPD patients of whom 29,708 were COPD-ICS (18.4\%). 67\% of COPD and $57 \%$ of COPD-ICS were male. Table 1 shows their demographic characteristics.

\section{Underlying COPD impact on $\mathrm{HZ}$}

There were $69,438 \mathrm{HZ}$ incident cases, corresponding to an incidence rate (IR) of 7.2 cases/1000 persons-year (95\% CI: 7.2-7.3). Of them, $4629 \mathrm{HZ}$ cases (6.7\%) were registered in the COPD non-ICS population (IR 11 cases/1000 persons-year; 95\% CI: 10.7-11.4) and 1164 (1.7\%) in COPD-ICS (IR 13 cases/1000 persons-year; 95\% CI: 12.3-13.8). HZ IR increased with age in all 3 groups and was higher in women (Table 2). HZ recurrence rates were 4.2, 5.1 and 5.2 per 100 persons-year

Table 1 Demographic characteristics for population $\geq 50$ years old in the Valencia Region from 2009 to 2014 $(n=2,289,485)$

\begin{tabular}{|c|c|c|c|}
\hline & Total Cohort & COPD patients (without ICS) & COPD-ICS patients \\
\hline Age (years) & N (\%) & $N(\%)$ & $N(\%)$ \\
\hline $50-59$ & $1,027,417$ & 26,724 & 4041 \\
\hline $60-69$ & 881,947 & 47,698 & 9181 \\
\hline $70-79$ & 699,885 & 59,753 & 12,928 \\
\hline$\geq 80$ & 414,036 & 47,289 & 11,366 \\
\hline \multicolumn{4}{|l|}{ Gender } \\
\hline Male & $1,061,732(46 \%)$ & $96,902(67 \%)$ & $16,913(57 \%)$ \\
\hline Female & $1,227,753(54 \%)$ & $47,628(33 \%)$ & $12,795(43 \%)$ \\
\hline Nationality & ${ }^{\mathrm{a}} N=1,774,750$ & ${ }^{\mathrm{a}} N=110,366$ & ${ }^{\mathrm{a}} N=23,425$ \\
\hline Spanish & $1,586,043(89 \%)$ & $103,658(94 \%)$ & $22,084(94 \%)$ \\
\hline Other & 188,707 (11\%) & $6708(6 \%)$ & $1341(6 \%)$ \\
\hline Urban status & ${ }^{a} N=2,261,243$ & ${ }^{\mathrm{a}} N=144,179$ & ${ }^{\mathrm{a}} N=29,698$ \\
\hline Urban & $2,191,837(97 \%)$ & 139,515 (97\%) & $28,619(96 \%)$ \\
\hline Rural & $69,406(3 \%)$ & $4664(3 \%)$ & $1079(4 \%)$ \\
\hline Social Exclusion & ${ }^{\mathrm{a}} N=1,739,725$ & ${ }^{\mathrm{a}} N=109,603$ & ${ }^{\mathrm{a}} N=23,301$ \\
\hline Risk & $202,365(12 \%)$ & $9521(9 \%)$ & $1754(8 \%)$ \\
\hline No risk & $1,537,360(88 \%)$ & $100,082(91 \%)$ & $21,547(92 \%)$ \\
\hline \multicolumn{4}{|l|}{ Comorbidities } \\
\hline Diabetes mellitus & $397,414(17 \%)^{b}$ & $43,553(30 \%)^{b}$ & $9415(32 \%)^{b}$ \\
\hline Heart Failure & $103,240(5 \%)^{b}$ & $25,977(18 \%)^{b}$ & $7101(24 \%)^{b}$ \\
\hline Total (\%) & $2,289,485$ & $144,530(6 \%)^{c}$ & $29,708(1.3 \%)^{c}$ \\
\hline
\end{tabular}

${ }^{a}$ Number of subjects with available information for each category

bercentages calculated considering total of each column as $100 \%$

cPercentages calculated considering total cohort (2289485) as 100\% 
Table 2 Incidence rates of HZ (per 1000 persons - per year) by age groups and sex in the Valencia region in 2009-2014

\begin{tabular}{|c|c|c|c|c|c|c|c|c|c|}
\hline \multirow[b]{2}{*}{ Age (years) } & \multicolumn{3}{|c|}{ Non-COPD } & \multicolumn{3}{|c|}{ COPD (without ICS) } & \multicolumn{3}{|c|}{ COPD-ICS } \\
\hline & Cases & $\mathbb{R}$ & $95 \% \mathrm{Cl}$ & Cases & $\mathbb{R}$ & $95 \% \mathrm{Cl}$ & Cases & $\mathbb{R}$ & $95 \% \mathrm{Cl}$ \\
\hline $50-59$ & 17,907 & 5.3 & $5.3-5.4$ & 452 & 7.4 & $6.7-8.1$ & 106 & 10.6 & $8.7-12.8$ \\
\hline $60-69$ & 19,638 & 7.3 & $7.2-7.4$ & 1155 & 10.3 & $9.7-10.9$ & 257 & 11.6 & $10.2-13.1$ \\
\hline $70-79$ & 16,149 & 8.3 & $8.2-8.4$ & 1667 & 12.0 & $11.4-12.6$ & 431 & 13.8 & $12.5-15.2$ \\
\hline$\geq 80$ & 9951 & 8.6 & $8.5-8.8$ & 1355 & 12.8 & $12.1-13.5$ & 370 & 14.2 & $12.8-15.7$ \\
\hline$\geq 50$ & 63,645 & 7.0 & $6.9-7.0$ & 4629 & 11.1 & $10.7-11.4$ & 1164 & 13.0 & $12.3-13.8$ \\
\hline \multicolumn{10}{|l|}{ Gender } \\
\hline Male & 23,057 & 5.6 & $5.5-5.7$ & 2932 & 10.3 & $10.0-10.7$ & 581 & 11.7 & $10.8-12.7$ \\
\hline \multirow[t]{2}{*}{ Female } & 40,588 & 8.1 & $8.0-8.2$ & 1697 & 12.6 & $12.0-13.2$ & 583 & 14.6 & $13.5-15.9$ \\
\hline & Cases & $\operatorname{ReR}$ & $95 \% \mathrm{Cl}$ & Cases & $\operatorname{ReR}$ & $95 \% \mathrm{Cl}$ & Cases & ReR & $95 \% \mathrm{Cl}$ \\
\hline$\geq 50$ & 6396 & 4.2 & $4.1-4.3$ & 612 & 5.1 & $4.7-5.1$ & 171 & 5.2 & $4.8-5.5$ \\
\hline
\end{tabular}

$\mathrm{Cl}$ Confidence Interval, ReR Recurrence rate per 100 persons (with a previous incident $\mathrm{HZ}$ ) - per year

IR Incidence Rate

for non-COPD (95\% CI: 4.1-4.3), COPD (95\% CI: 4.7-5. 1 ) and COPD-ICS (95\% CI: 4.8-5.5) respectively.

The adjusted risk of $\mathrm{HZ}$ increased by $45 \%$ among COPD patients and by $61 \%$ among COPD-ICS with respect to non-COPD; relative risk (RR) 1.45, 95\% CrI: $1.41-1.5$; RR 1.61, 95\% CrI: $1.52-1.7$ respectively (Table 3). The HZ risk was $36 \%$ higher in women; it increased with age and in patients with diabetes (20\%) and heart failure (25\%).

COPD patients with HZ utilized more healthcare resources than non-COPD patients (Table 4): they had 5\% more outpatient visits, were prescribed $25 \%$ more antivirals and had higher risk for hospitalization with a $\mathrm{HZ}$ code at any diagnostic position (Odds ratio [OR] 2.7, 95\% CI: 2.2-3.2). COPD-ICS subjects had 7\% more outpatient visits, $45 \%$ more antiviral prescriptions and higher risk for hospitalization with a $\mathrm{HZ}$ code at any diagnostic position (OR 2.6, 95\% CI: 1.8-3.6). Length of hospital stay and duration of sick leave were not significantly higher in COPD than in non-COPD patients.

\section{$\mathrm{HZ}$ impact on underlying COPD}

Outpatient visits (RR 1.02; 95\% CI: 0.96-1.08) and number (OR 1.13; 95\% CI: 0.96-1.33) and length (OR 1.19; 95\% CI: 1-1.42) of hospitalizations for COPD were higher after an HZ episode (Table 5), although the increase was not statistically significant. These results suggest that $\mathrm{HZ}$ may have a small and non-significant impact on the underlying COPD.

\section{Discussion}

Patients with COPD are more susceptible to infections than those without [21]. This population-based study demonstrated that COPD increases the risk and severity of $\mathrm{HZ}$ episodes and indicated that $\mathrm{HZ}$ may contribute to
COPD exacerbations resulting to an increase in healthcare resources consumption.

In our study, the IR of HZ was higher in COPD patients older than 50 years and was almost double in COPD-ICS compared to those without COPD. Poisson regression analysis showed that the adjusted HZ RR was 1.5 and 1.6 times higher in COPD and in COPD-ICS patients respectively than in non-COPD. These data are consistent with a previous Spanish study [8], although their adjusted IR ratio was slightly lower than ours, probably due to methodological differences. For instance, they used databases from primary care, whereas

Table $3 \mathrm{HZ}$ adjusted relative risk for COPD and COPD-ICS patients in relation with Non-COPD

\begin{tabular}{lll}
\hline & & Relative Risk (95\% Crl) \\
\hline COPD & NO COPD & 1 \\
& COPD & $1.45(1.41-1.5)$ \\
Sex & COPD-ICS & $1.61(1.52-1.71)$ \\
& Male & 1 \\
Age & Female & $1.36(1.33-1.38)$ \\
(Years) & $50-59$ & 1 \\
& $60-69$ & $1.38(1.34-1.41)$ \\
& $70-79$ & $1.53(1.49-1.57)$ \\
Comorbidity & $80+{ }^{+}$ & $1.49(1.45-1.54)$ \\
Diabetes & & 1 \\
& No Diabetes & $1.2(1.17-1.22)$ \\
HF & Diabetes & 1 \\
& No HF & $1.25(1.2-1.3)$
\end{tabular}

Relative risk estimates and $95 \%$ credible intervals $(95 \% \mathrm{Crl})$ for the association between $\mathrm{HZ}$ incidence and COPD, controlling for sex, age, comorbidities (Diabetes and HF), health department (as a random effect) and calendar year, using Bayesian Poisson regression 
Table $4 \mathrm{HZ}$-Health care resources consumption by global COPD (with and without ICS) and COPD-ICS patients in relation with Non-COPD

\begin{tabular}{lll}
\hline & COPD & COPD-ICS \\
\hline Outpatient visits for HZ & RR $(95 \% \mathrm{Cl})$ & \\
& $1.05(1.03-1.08)$ & $1.07(1.03-1.1)$ \\
Medication for HZ & RR (95\% Cl) & \\
& $1.25(1.19-1.31)$ & $1.45(1.32-1.59)$ \\
Hospitalizations $^{\mathrm{a}}$ & OR (95\% Cl) & \\
& $2.66(2.17-3.24)$ & $2.59(1.80-3.62)$ \\
Length of hospital stay & Mean ratio (95\% Cl) & \\
Sick leave & $1.21(0.97-1.52)$ & $1.26(0.84-1.87)$ \\
& Mean ratio (95\% Cl) & \\
\hline
\end{tabular}

$C$ Confidence interval, $R R$ Relative risk, $O R$ Odds ratio

${ }^{a}$ Hospitalizations with a HZ ClE-9 code in any diagnostic position

we collected data from both, primary care and hospitalizations. Also they included population as young as 18 years old.

Various studies have identified COPD as risk factor for $\mathrm{HZ}[7,23,24,30]$ because of systemic immune disturbances in COPD. Recently it was demonstrated that imbalances between subsets of CD8+ peripheral blood T-cells contribute to the pathogenesis of the immune response dysfunction in COPD [31, 32]. Cellular immunity is crucial to maintain VZV in a latent state and impede its reactivation [2]. These results suggest that COPD patients might have an impaired cell-mediated immunity. We also found higher $\mathrm{HZ}$ recurrence rate in COPD than in non-COPD subjects, which seems to support this hypothesis.

Yang et al. also found higher HZ risk in COPD patients using ICS [24], the risk being higher in patients using oral corticosteroids. However, other studies have not found this association between HZ and ICS [23, 25]. Ernst et al. pointed to methodological problems, such as insufficient sample size and outcome or exposure misclassification. Two reasons could be responsible for this

Table 5 COPD-Health care resources consumption during 6 months pre and 6 months post-HZ for COPD cohort

\begin{tabular}{lll}
\hline & PRE-HZ & POST-HZ \\
\hline Outpatient visits for COPD & RR $(95 \% \mathrm{Cl})$ & \\
Hospitalizations $^{\text {a }}$ & 1 & $1.02(0.96-1.08)$ \\
& OR $(95 \% \mathrm{Cl})$ & \\
Length of hospital stay & 1 & $1.13(0.96-1.33)$ \\
& Mean ratio $(95 \% \mathrm{Cl})$ \\
Medication (ICS) & 1 & $1.19(1-1.42)$
\end{tabular}

$1 \quad 0.98(0.76-1.25)$

${ }^{\mathrm{a}}$ Hospitalizations with a COPD CIE-9 code in any diagnostic position kind of association. Firstly, ICS possibly affects cellular immunity in COPD-ICS patients, which could increase the HZ risk. Secondly and equally likely, patients using ICS might have a more severe COPD state, making them more susceptible to develop HZ.

To our knowledge, this is the first time that healthcare resources consumption due to $\mathrm{HZ}$ is compared between non-COPD and COPD patients. COPD patients attended more frequently outpatient clinics due to $\mathrm{HZ}$ than non-COPD and received more antiviral medications. This amount increased in COPD-ICS patients. These data indicate that $\mathrm{HZ}$ episodes were more severe in COPD patients and even more in COPD-ICS.

Our results support a recent prospective cohort study which demonstrates that chronic conditions as diabetes, cardiovascular and respiratory diseases increase zosterrelated pain and impact the quality of life in immunocompetent zoster patients aged 50 years or older [33]. However, this study was not powered to detect differences between the groups of patients with and without underlying conditions.

Our study also showed a non-statistically significant tendency to more frequent visits to primary care clinics, higher number of hospitalizations and longer hospital stays due to COPD after the HZ episode. Although inconclusive, these results could indicate a negative relationship between $\mathrm{HZ}$ and COPD.

Considering the presented results, HZ/PHN vaccination could be helpful when handling these patients. It reinforces the cell-mediated immunity against the latent VZV, preventing thus its reactivation and the related complications. Currently, the vaccine is used to prevent $\mathrm{HZ} / \mathrm{PHN}$ in USA and various European countries in patients older than 50 years and in those with COPD, diabetes or cardiovascular disease. A recent Spanish study [34] revealed that a vaccination strategy including at least $30 \%$ of adults older than 50 years would be cost effective and would increase the benefits of the vaccination program for adults older than 65 years.

Our study has some limitations. As in other studies using routinely collected data, potential codification errors may occur because the data were not created for research purposes. In our case, qualified personnel codify MBDS with almost no mistakes and positive predictive value of those databases' diagnostic codes resulted high in previous evaluations $[6,10,35]$. Our databases did not allow us to identify the severity of COPD; therefore, we selected patients using ICS considering them to suffer with more severe COPD than patients without ICS treatment. Information about treatment with oral corticosteroids was not available from our database as they are more likely to be administered at hospitals; our pharmacy database collects prescriptions and dispensations from the outpatient services. 


\section{Conclusion}

These results reflect that COPD patients have higher risk of suffering $\mathrm{HZ}$ and consume more healthcare resources compared to non-COPD patients, which could be the result of a more severe HZ. COPD patients should be considered as a significant risk group for $\mathrm{HZ}$. Our study could represent the first step to assess the impact of a future implementation of the $\mathrm{HZ}$ vaccine in COPD population.

\section{Additional files}

Additional file 1: Medication registered for $\mathrm{HZ}$ and PHN (ATC codes). Table listing the ATC codes, drug type and drug name of the medication registered for $\mathrm{HZ}$ and $\mathrm{PHN}$. (DOCX $14 \mathrm{~kb}$ )

Additional file 2: Generalized linear models. Table including the different statistical GLM utilized to compare the COPD and the nonCOPD populations depending on the outcome variable. (DOCX 15 kb)

\section{Abbreviations}

$\mathrm{Cl}$ : Confidence interval; COPD: Chronic obstructive pulmonary disease; COPDICS: Chronic obstructive pulmonary disease with inhaled corticosteroids; Crl: Credible interval; GAIA: Care provision management (Sistema de información farmacéutica); GLM: Generalized linear models; HF: Heart failure; HZ: Herpes zoster; ICD-9-CM: International classification of diseases 9th. Clinical modification; IR: Incidence rate; MBDS: Minimum Basic Data Set (Conjunto mínimo básico de datos); OR: Odds ratio; PHN: Post-herpetic neuralgia; ReR: Recurrence rate; RHS: Regional Health System; RR: Relative risk; SIA: Ambulatory information system (Sistema de información ambulatoria); SIP: Personal identification system; VZV: Varicella zoster virus

\section{Funding}

This study was funded by SPMSD. The company had no role in the analysis or discussion of the results.

\section{Availability of data and materials}

The dataset analyzed during the current study are available in: https:// drive.google.com/drive/folders/OB6IsFI2JIL8jaGZpMElwVGIJd0k?usp=sharing

\section{Authors' contributions}

JDD is the guarantor of the paper, taking responsibility for the integrity of the work as a whole, from inception to published article. CMQ contributed to study conception and design; data acquisition, analysis, and interpretation; drafting the article or revising it critically for important intellectual content; and final approval of the version to be published. CMQ takes responsibility for the integrity of the data and the accuracy of the data analysis and serves as principal author. MLL contributed to data acquisition, data cleaning, analysis and interpretation; drafting the article or revising it critically for important intellectual content; and final approval of the version to be published. JDD contributed to study design; drafting the article or revising it critically for important intellectual content; and final approval of the version to be published. All authors have read and approved the manuscript.

\section{Ethics approval and consent to participate}

The study protocol was approved by the Ethics Committee of Dirección General de Salud Pública / Centro Superior de Investigación en Salud Pública. In order to protect personal data, the original datasets were dissociated by the database's managers. Moreover, consent was waived by the IRB (Ethics Committee of Dirección General de Salud Pública / Centro Superior de Investigación en Salud Pública).

\section{Competing interests}

JDD and his institution received research grants from SPMSD related to $\mathrm{HZ}$ vaccine. He also acted as advisor for these vaccines to GSK and SPMSD. CMQ has attended to several congresses whose registration, travel and accommodation costs have been covered by SPMSD. MLL has reported that no potential conflicts of interest exist with any companies/organizations whose products or services may be discussed in this article.

\section{Publisher's Note}

Springer Nature remains neutral with regard to jurisdictional claims in published maps and institutional affiliations.

\section{Author details}

${ }^{1}$ Vaccine Research. Fundación para el Fomento de la Investigación Sanitaria y Biomédica de la Comunitat Valenciana, FISABIO-Public Health, Valencia, Spain. ${ }^{2}$ Universidad Católica de Valencia San Vicente Mártir, Carrer de Quevedo, 2, 46001 València, Spain. ${ }^{3}$ Vaccine Research Area, FISABIO-Public Health, Avda. Cataluña, 21, 46020 Valencia, Spain.

Received: 4 August 2017 Accepted: 30 April 2018

Published online: 03 May 2018

References

1. Drolet M, Brisson M, Schmader KE, Levin MJ, Johnson R, Oxman MN, Patrick D, Blanchette C, Mansi JA. The impact of herpes zoster and postherpetic neuralgia on health-related quality of life: a prospective study. CMAJ. 2010; 182(16):1731-6.

2. Arvin AM. Humoral and cellular immunity to varicella-zoster virus: an overview. J Infect Dis. 2008;197:S58-60.

3. Johnson RW, Rice ASC. Postherpetic neuralgia. N Engl J Med. 2014; 371(16):1526-33.

4. Gater A, Uhart M, McCool R, Preaud E. The humanistic, economic and societal burden of herpes zoster in Europe: a critical review. BMC Public Health. 2015;15:1514.

5. Schmader K. Herpes zoster in older adults. Clin Infect Dis. 2001;32(10): 1481-6.

6. Morant-Talamante N, Diez-Domingo J, Martinez-Ubeda S, Puig-Barbera J, Aleman-Sanchez S, Perez-Breva L. Herpes zoster surveillance using electronic databases in the Valencian community (Spain). BMC Infect Dis. 2013;13:463.

7. Forbes HJ, Bhaskaran K, Thomas SL, Smeeth L, Clayton T, Langan SM. Quantification of risk factors for herpes zoster: population based casecontrol study. BMJ (Clinical research ed). 2014;348:g2911.

8. Esteban-Vasallo MD, Dominguez-Berjon MF, Gil-Prieto R, Astray-Mochales J, de Miguel AG. Sociodemographic characteristics and chronic medical conditions as risk factors for herpes zoster A population-based study from primary care in Madrid (Spain). Hum Vaccin Immunother. 2014; 10(6):1650-60.

9. Forbes HJ, Bhaskaran K, Thomas SL, Smeeth L, Clayton T, Mansfield K, Minassian C, Langan SM. Quantification of risk factors for postherpetic neuralgia in herpes zoster patients: a cohort study. Neurol. 2016;87(1): 94-102.

10. Muñoz-Quiles C, López-Lacort M, Ampudia-Blasco FJ, Díez-Domingo J. Risk and impact of herpes zoster on patients with diabetes: a population-based study, 2009-2014. Hum Vaccin Immunother. 2017;13(11):2606-11.

11. Shaw JE, Sicree RA, Zimmet PZ. Global estimates of the prevalence of diabetes for 2010 and 2030. Diabetes Res Clin Pract. 2010;87(1):4-14.

12. Vestbo J, Hurd SS, Agusti AG, Jones PW, Vogelmeier C, Anzueto A, Barnes PJ, Fabbri LM, Martinez FJ, Nishimura M, et al. Global strategy for the diagnosis, management, and prevention of chronic obstructive pulmonary disease GOLD executive summary. Am J Respir Crit Care Med. 2013;187(4):347-65.

13. Kuhdari P, Zorzoli E, D'Alo GL, Brosio F, Bonanni P, Valente S, Gabutti G, Franco $E$. The public health importance of vaccinations in the elderly: an evidence-based quide. Ig Sanita Pubbl. 2016;72(3):265-92.

14. Maggi S, Gabutti G, Franco E, Bonanni P, Conversano M, Ferro A, Lazzari M, Rossi A, Scotti S, Vitale F, et al. Preventing and managing herpes zoster: key actions to foster healthy aging. Aging Clin Exp Res. 2015;27(1):5-11.

15. Oxman MN, Levin MJ, Johnson GR, Schmader KE, Straus SE, Gelb LD, Arbeit RD, Simberkoff MS, Gershon AA, Davis LE, et al. A vaccine to prevent herpes zoster and postherpetic neuralgia in older adults. N Engl J Med. 2005; 352(22):2271-84.

16. Harpaz R, Ortega-Sanchez IR, Seward JF. Advisory Committee on Immunization Practices Centers for D, Control and P. Prevention of herpes zoster: recommendations of the Advisory Committee on Immunization Practices (ACIP). MMWR. Recomm Rep: Morb Mortal Wkly Rep. Recomm Reps / CDC. 2008;57((RR-5)):1-30. quiz CE32-34 
17. Tseng HF, Smith N, Harpaz R, Bialek SR, Sy LS, Jacobsen SJ. Herpes zoster vaccine in older adults and the risk of subsequent herpes zoster disease. JAMA. 2011;305(2):160-6.

18. Langan SM, Smeeth L, Margolis DJ, Thomas SL. Herpes zoster vaccine effectiveness against incident herpes zoster and post-herpetic neuralgia in an older US population: a cohort study. PLoS Med. 2013;10(4):e1001420.

19. Gabutti G, Valente N, Kuhdari P, Lupi S, Stefanati A. Prevention of herpes zoster and its complications: from the clinic to the real-life experience with the vaccine. J Med Microbiol. 2016;65:1363-9.

20. Cosio MG, Saetta M, Agusti A. MECHANISMS OF DISEASE Immunologic aspects of chronic obstructive pulmonary disease. N Engl J Med. 2009; 360(23):2445-54

21. Brusselle GG, Joos GF, Bracke KR. Chronic Obstructive Pulmonary Disease 1 New insights into the immunology of chronic obstructive pulmonary disease. Lancet. 2011:378(9795):1015-26.

22. Lee S-H, Goswami S, Grudo A, Song L-z, Bandi V, Goodnight-White S, Green L, Hacken-Bitar J, Huh J, Bakaeen F, et al. Antielastin autoimmunity in tobacco smoking-induced emphysema. Nat Med. 2007;13(5):567-9.

23. Patel ARC, Karmali S, Donaldson GC, Goldring JJP, Wedzicha JA, Hurst JR. Prevalence of herpes zoster in COPD and relationships with inhaled corticosteroids, exacerbation frequency and FEV1. Am J Respir Crit Care Med. 2010:181: Abstract number A5926.

24. Yang Y-W, Chen Y-H, Wang K-H, Wang C-Y, Lin H-W. Risk of herpes zoster among patients with chronic obstructive pulmonary disease: a populationbased study. Can Med Assoc J. 2011;183(5):E275-80.

25. Ernst $P$, Dell'Aniello S, Mikaeloff Y, Suissa S. Risk of herpes zoster in patients prescribed inhaled corticosteroids: a cohort study. BMC Pulm Med. 2011;11: 59. https://doi.org/10.1186/1471-2466-11-59.

26. Instituto Nacional de Estadística: Cifras oficiales de población resultantes de la revisión del Padrón municipal a 1 de Enero de 2014. 2014; http://www. ine.es/dynt3/inebase/es/index.html?padre $=517 \& d h=1$.

27. Indra Sistemas SA. Proyecto Abucasis Conselleria Sanitat Valencia. http:// www.indracompany.com/sectores/sanidad/proyectos/179/proyectoabucasis-conselleria-de-sanitat-valencia. Accessed 1 Jan 2016.

28. Guignard AP, Greenberg M, Lu C, Rosillon D, Vannappagari V. Risk of herpes zoster among diabetics: a matched cohort study in a US insurance claim database before introduction of vaccination, 1997-2006. Infection. 2014; 42(4):729-35.

29. Munoz-Quiles C, Lopez-Lacort M, Ubeda-Sansano I, Aleman-Sanchez S, Perez-Vilar S, Puig-Barbera J, Diez-Domingo J. Population-based analysis of bronchiolitis epidemiology in Valencia, Spain. Pediatr Infect Dis J. 2016:35(3):275-80

30. Joesoef RM, Harpaz R, Leung J, Bialek SR. Chronic medical conditions as risk factors for herpes zoster. Mayo Clin Proc. 2012:87(10):961-7.

31. Chen L, Chen G, Zhang MQ, Xiong XZ, Liu HJ, Xin JB, Zhang JC, Wu JH, Meng ZJ, Sun SW. Imbalance between subsets of CD8(+) peripheral blood T cells in patients with chronic obstructive pulmonary disease. PeerJ. 2016;4:14.

32. Bhat TA, Panzica L, Kalathil SG, Thanavala Y. Immune dysfunction in patients with chronic obstructive pulmonary disease. Ann Am Thorac Soc. 2015; 12(Suppl 2):S169-75.

33. Torcel-Pagnon L, Bricout H, Bertrand I, Perinetti E, Franco E, Gabutti G, Volpi A. Impact of underlying conditions on zoster-related pain and on quality of life following zoster. J Gerontol A Biol Sci Med Sci. 2017;72(8):1091-7.

34. Lopez-Belmonte JL, Cisterna R, Gil de Miguel A, Guillmet C, Bianic F, Uhart $M$. The use of Zostavax in Spain: the economic case for vaccination of individuals aged 50years and older. J Med Econ. 19(6):576-86.

35. Pérez-Vilar S, Díez-Domingo J, Puig-Barberá J, Gil-Prieto R, Romio S. Intussusception following rotavirus vaccination in the Valencia region, Spain. Hum Vaccin Immunother. 2015:11(7):1848-52.

\section{Ready to submit your research? Choose BMC and benefit from:}

- fast, convenient online submission

- thorough peer review by experienced researchers in your field

- rapid publication on acceptance

- support for research data, including large and complex data types

- gold Open Access which fosters wider collaboration and increased citations

- maximum visibility for your research: over $100 \mathrm{M}$ website views per year

At BMC, research is always in progress.

Learn more biomedcentral.com/submissions 